\title{
PROFESSORAS DE EDUCAÇÃO INFANTIL E MUDANÇA: REFLEXÕES A PARTIR DE BAKHTIN
}

SONIA KRAMER

sokramer@edu.puc-rio.br

\section{RESUMO}

Este texto - escrito a partir de entrevistas coletivas realizadas na pesquisa Formação de profissionais da educação infantil no Estado do Rio de Janeiro: concepções, políticas e modos de implementação - tem seu foco no tema e referencial teórico-metodológico da mudança. Esse referencial baseia-se na concepção de linguagem de Bakhtin, preciosa para a compreensão da originalidade com que o tema da mudança foi abordado pelos participantes: a metáfora de sacudir. Conceitos de ambivalência dialética e dialogismo revelaram-se ferramentas teóricas fundamentais para a pesquisa. A idéia de que é preciso mudar, acompanhada pelo desejo de mudar, emergiu em quase todas as entrevistas. Mas foi em entrevista feita com nove professoras que a mudança foi mencionada como se constituísse a ação educativa: uma das professoras entrevistadas relatou que não concordava com a prática vivida e resolveu "dar um sacode no pedagógico".

EDUCAÇÃO INFANTIL - FORMAÇÃO PROFISSIONAL - BAKHTIN - PROFESSORAS

\section{ABSTRACT}

PRIMARY EDUCATION TEACHING PROFESSIONALS AND CHANGE: REFLECTIONS ON BAKHTIN AND BEYOND. This text - based on collective interviews conducted in the study Formação de profissionais da educação infantil no Estado do Rio de Janeiro: concepções, políticas e modos de implementação [Primary Education Professional Training in the State of Rio de Janeiro: concepts, policies and implementation modes] - focuses on the theoretic and methodological theme and reference named change. The theoretic reference basis is Bakhtin's conception of language, invaluable for understanding the originality with which the subject of change was approached by participants: a metaphor for shaking. The concepts of dialectic ambivalence and dialogism presented themse/ves as fundamental theoretic tools for the study. The idea of the need for change, accompanied by the desire to change, emerged in almost all interviews. However, it was in an interview conducted with nine teaching professionals that change was mentioned as the educational action itself: one of the teachers interviewed reported that she did not agree with the practice experienced and decided "to give pedagogy a shake".

UPBRINGING-VOCATIONAL TRAINING-BAKHTIN-WOMENTEACHERS

Todas as relações têm caráter lógico, enquanto eu em tudo ouço vozes e relaçóes dialógicas entre elas.

Bakhtin, 1982, p. 392

Este texto foi apresentado originalmente na I Ia Conferência Internacional sobre Bakhtin, em Curitiba 2003 
O objetivo deste trabalho é apresentar uma apropriação teórico-metodológica de conceitos de Mikhail Bakhtin, que tem sido feita no interior da pesquisa Formação de profissionais da educação infantil no Estado do Rio de Janeiro: concepções, políticas e modos de implementação'. Inicialmente, sintetizo as principais questões do referencial teórico da pesquisa. Em seguida, detenho-me em aspectos metodológicos, em particular nas entrevistas. No terceiro momento, focalizo um aspecto que emergiu em uma das entrevistas coletivas - a concepção de mudança - e analiso como o conceito de ambivalência dialética de Bakhtin ajudou a compreendê-lo e problematizá-lo. Explicito, pois, que o interesse pela teoria de Bakhtin é filosófico e epistemológico. Interessam-me seus estudos pelas contribuições que oferecem à pesquisa nas ciências humanas e sociais.

\section{O REFERENCIAL TEÓRICO: LINGUAGEM, NARRATIVA E EXPERIÊNCIA}

Até o momento em que foi apropriado, o discurso não se encontra em uma língua neutra e impessoal (pois não é do dicionário que ela é tomada pelo falante!), ela está nos lábios de outrem, nos contextos de outrem e a serviço das intenções de outrem: e é lá que é preciso que ele seja isolado e feito próprio.

Bakhtin, 1988a, p. 21

O compromisso desta pesquisa, com as ciências humanas, é o de encontrar aquilo que se perde quando o homem é transformado em objeto e as histórias das pessoas são esquecidas. Isso significa perceber as pessoas reconstituindo-se como sujeitos e, nesse processo, reconstituindo sua cultura e história, escutando o que não pode ser expresso e levando em consideração o que foi deixado de fora. Histórias de vida são consideradas memória coletiva do passado, consciência crítica do presente e premissa operativa do futuro. De acordo com Bakhtin (1988), produção e recepção de significados é o que constitui a linguagem que tem dimensões dialógicas e ideológicas historicamente determinadas. Toda palavra tem intenções, significados; para entender o discurso (o texto falado ou escrito), o contexto precisa ser entendido. A compreensão implica não só a identificação da linguagem formal e dos sinais normativos da língua, mas também os subtextos, as intenções que não se encontram explicitadas: "Não são palavras o que pronunciamos ou escutamos, mas

I A pesquisa foi realizada com apoio do Conselho Nacional do Desenvolvimento Cientííco e Tecnológico - CNPq - e da Fundação Carlos Chagas Filho de Amparo à Pesquisa do Estado do Rio de Janeiro - Faperj. 
verdades ou mentiras, coisas boas ou más, importantes ou triviais, agradáveis ou desagradáveis... A palavra está sempre carregada de um conteúdo e um sentido ideológico e vivencial" (Bakhtin, 1988, p.95). O discurso tem sempre um significado e uma direção que são vivos; as palavras contêm valores e forças ideológicas: aqui se situa a abordagem histórica da linguagem. Por outro lado, a comunicação de significados implica comunidade; sempre nos dirigimos ao outro, e o outro não tem apenas um papel passivo; o interlocutor participa ao atribuir significado à enunciação. Bakhtin entende que a linguagem é social; ela é essencial para a existência humana. De acordo com sua teoria, não é a experiência que organiza a expressão; na verdade, a expressão precede e organiza a experiência, dando-lhe forma e direção.

Outra importante referência para o arcabouço teórico da pesquisa pode ser encontrada nas idéias filosóficas de Walter Benjamin e particularmente no conceito de experiência, no qual se discute o declínio da arte de narrar no mundo moderno:

...o narrador é um homem que sabe dar conselhos. Mas, se "dar conselhos" parece hoje algo de antiquado é porque as experiências estão deixando de ser comunicáveis. Em conseqüência, não podemos dar conselhos nem a nós mesmos nem aos outros. Aconselhar é menos responder a uma pergunta que fazer uma sugestão sobre a continuação de uma história que está sendo narrada. (1987, p.200)

Resgatar o passado significa ter uma compreensão diferente da história; o passado é importante para rever o presente, para colocá-lo numa condição crítica, conferir-Ihe nova significação. E a história humana é baseada nessa descontinuidade; somente os seres humanos têm história e por isso a linguagem é necessária. Como o homem é gerado na cultura da mesma forma que a produz, ele pode fazer e contar a história. Podemos, então, repensar o passado para dar um novo significado à história. Por outro lado, nos seus escritos, Benjamin (1987) se refere a dois personagens centrais na modernidade que contribuem para pensar a tarefa do pesquisador: o cronista e o colecionador. "O cronista que narra os acontecimentos, sem distinguir entre os grandes e os pequenos, leva em conta a verdade de que nada do que um dia aconteceu pode ser considerado perdido para a história" (p.223).

E como um colecionador, o pesquisador procura, observa, registra, fotografa, reúne as interações humanas, para investigá-las, quer dizer, para colecioná-las; a relação dialética entre ordem e desordem precisa ser estabelecida. Falando de outro lugar (o da literatura), Clarice Lispector dirá: "Escrevo-te em desordem, bem sei. Mas é como vivo. Eu só trabalho com achados e perdidos" (1973, p.87). Ou: "Um 
instante me leva insensivelmente a outro e o tema atemático vai se desenrolando sem plano mas geométrico como as figuras sucessivas num caleidoscópio" (p. I6).

Como pesquisadora de um campo das ciências humanas - a educação considero importante escutar/ouvir e observar/ver, levando em conta tanto a racionalidade como a sensibilidade a fim de compreender a história. A teoria crítica ajuda-nos a ver a cultura de uma maneira diversa, a contrapelo - como diz Clarice; ajuda a estabelecer outras relações e a perceber ambigüidades. Do mesmo modo, a concepção de linguagem de Bakhtin fornece o arcabouço teórico para entender as relações na sua ambivalência e pluralidade.

\title{
A PESQUISA, SEU CONTEXTO E PROCEDIMENTOS
}

\author{
O texto só vive em contato com outro texto (contexto). \\ Somente em um ponto de contato é que surge a luz que aclara \\ para trás e para frente, fazendo com que o texto participe de um \\ diálogo... Por trás desse contato, há o contato de pessoas e não \\ de coisas. Bakhtin, 1992, p. 404-405
}

A pesquisa, desenvolvida desde 1999, tem quatro estratégias metodológicas:

I. Um questionário foi enviado a todas as secretarias de educação dos municípios, solicitando dados sobre as condições da educação infantil pública, programas de formação de professores que eram implementados e os problemas ou dificuldades enfrentados tanto na educação infantil quanto na formação de professores. O questionário, organizado em 75 quesitos, foi respondido por profissionais responsáveis pela educação infantil. A análise dos dados coletados foi concluída e os resultados, sistematizados em um relatório, apresentados aos responsáveis pela educação infantil dos municípios e distribuídos para todas as secretarias de educação (Kramer et al., 200I).

2. Entrevistas foram realizadas com o objetivo de conhecer as histórias de vida e de formação dos profissionais. Entrevistamos professores que são responsáveis pelas políticas públicas de educação infantil em dez cidades da Região Metropolitana do Rio de Janeiro. Esses municípios foram também convidados para as entrevistas coletivas realizadas posteriormente².

2 As cinco entrevistas coletivas foram planejadas e preparadas cuidadosamente. Os participantes foram convidados por carta e por telefone. A carta explicava os objetivos e procedimentos da pesquisa. 
3. Textos de documentos oficiais e propostas curriculares foram reunidos e analisados (Nascimento, 200 I). Nesse procedimento, ao buscar conhecer as propostas, tentamos identificar concepções teóricas (de infância, educação infantil e formação de professores), políticas e modos de implementação das ações: projetos de educação infantil e de formação.

4. Estudos de caso, na forma de monografias de especialização, dissertações de mestrado e teses de doutorado, têm sido realizados em creches, préescolas e turmas de educação infantil que funcionam em escolas maiores. Nessa vertente, produzem-se trabalhos acadêmicos que focalizam municípios do Estado do Rio de Janeiro e de outros estados da federação.

Este texto aborda as entrevistas, centrando-se em uma entrevista coletiva.

\section{ENTREVISTAS INDIVIDUAIS E COLETIVAS}

Tudo o que me diz respeito, a começar por meu nome, e que penetra em minha consciência, vem-me do mundo exterior, da boca dos outros (da mãe), etc. e me é dado com a entonação,

com o tom emotivo dos valores deles. Tomo consciência de mim, originalmente, através dos outros: deles recebo a palavra,

a forma e o tom que servirão à formação original da representação que terei de mim mesmo.

Bakhtin, 1992, p. 278

Dois tipos de entrevistas foram realizados: individuais e coletivas. Tal estratégia permitiu observar uma significativa diferença no que diz respeito à diversidade, hierarquia e distribuição de poder. Nos dois tipos de entrevistas, o compromisso e desejo eram garantir os diálogos. Sabendo de uma forte ligação entre história de vida, subjetividade e narrativa, conduzimos as entrevistas como espaço de narrativa entre os profissionais entrevistados e pesquisadores. Percebemos que a posição estabelecida entre pesquisador e pesquisados - o lugar de onde falam - é muito diferente nos dois tipos. Durante as entrevistas coletivas, o diálogo, a narrativa da experiência e a exposição de idéias divergentes ocorreram com intensidade muito maior, na medida em que professores puderam falar e também escutar uns aos outros. Além disso, como não só o pesquisador detém autoridade para fazer perguntas ou comentários sobre a fala dos entrevistados, a influência do poder e da posição hierárquica foram minimizados; problemas foram apresentados; o conhecimento, compartilhado e confrontado; a diversidade, percebida face a face. Entre- 
vistas individuais e coletivas ofereceram diferentes condições de produção de discurso e favoreceram a pesquisadores e pesquisados lugar e ponto de vista diferentes. Nas entrevistas coletivas, enriqueceu-se a situação dialógica, análises foram mais profundas e substanciais e, acima de tudo, a perplexidade foi expressa: professores com diversas ou opostas condições de trabalho e trabalhando sob políticas públicas de infância mais ou menos favoráveis, precisaram lidar com essa diversidade e encarar as falhas, os fracassos e a precariedade dos outros, bem como se deparar com a própria fragilidade.

\section{ENTREVISTAS COLETIVAS: CONTRIBUIÇÃO PARA APRENDER COM A DIVERSIDADE E COM O OUTRO}

Tudo o que dá valor ao dado do mundo, tudo o que atribui um valor autônomo à presença no mundo, está vinculado ao outro.... éa respeito do outro que se inventam histórias, é pelo outro que se derramam lágrimas, é ao outro que se erigem monumentos; apenas os outros povoam os cemitérios; a memória só conhece só preserva e reconstitui o outro... Bakhtin, 1992, p. 126.

Todas as entrevistas seguiram um planejamento. Cada entrevista reuniu profissionais de sete ou oito municípios; de cada secretaria municipal de educação, dois educadores - responsáveis pela educação infantil - foram convidados. Dois profissionais da Secretaria Estadual de Educação do Rio de Janeiro foram também convidados para cada entrevista coletiva. A interação de pesquisadores e participantes foi intensa e amena; este clima parece ter influenciado positivamente a abordagem. Como os profissionais foram convidados, isso pode também ter contribuído para o ambiente dialógico. A estratégia pode ter assegurado ao discurso seu caráter de acontecimento (Bakhtin, 1988).

No caso desta pesquisa, a interação nas entrevistas coletivas constituiu importante experiência para pesquisadores e participantes. Tendo como objetivo identificar pontos de vista dos entrevistados; reconhecer aspectos polêmicos (a respeito dos quais não há concordância); provocar o debate; estimular os participantes a tomarem consciência de sua situação e condição e a pensarem criticamente sobre elas, as entrevistas coletivas favoreceram que certos temas fossem colocados em discussão, problematizando o objeto da pesquisa (que é sempre, nas ciências humanas, um sujeito que fala). Enfrentamos com essa estratégia metodológica a delicada questão da alteridade, do conhecimento do outro. Como diz Bakhtin, 
Quando contemplo um homem situado fora de mim e à minha frente, nossos horizontes concretos, tais como são efetivamente vividos por nós dois, não coincidem. Por mais perto de mim que possa estar esse outro, sempre serei e saberei algo que ele próprio, na posição que ocupa, e que o situa fora de mim e à minha frente, não pode ver. (1992, p.43)

As entrevistas coletivas ajudaram a identificar conflitos sem esconder idéias divergentes ou posições antagônicas. Durante as entrevistas, os pesquisadores procuraram explicitar palavras, expressões ou conceitos, usados com significados conflitantes ou ambíguos, a fim de gerar - entre participantes e pesquisadores processos de ressignificação. Assim, os grupos puderam refletir sobre idéias compartilhadas e histórias que foram contadas, repensando seus sentidos e revendo atividades, problemas e iniciativas cotidianas. Após cada entrevista, pudemos analisar as questões controversas e ambigüidades encontradas.

Como destacado em outros textos (Kramer, 2003; Kramer et al., 2002), nas entrevistas coletivas, mais do que nas individuais, as pessoas falaram e escutaram; a influência institucional pareceu diluir-se ou diminuir; a linguagem produzida (o discurso) pareceu revelar maior autenticidade, favorecendo a dimensão pessoal ao lado da profissional; problemas e valores estiveram mais presentes nas coletivas. Este foi um importante aspecto já que as pessoas entrevistadas ocupavam cargos hierárquicos como responsáveis pela educação infantil nas secretarias municipais e estadual de educação. Nas entrevistas individuais, a linguagem pareceu mais limpa, como se o entrevistado precisasse expor a realidade na qual acreditava (ou que desejava), escondendo ou omitindo falhas, faltas, erros. Nos grupos, os relatos traziam dificuldades e frustrações, como se a pessoa entrevistada sentisse maior confiança na audiência coletiva; além disso, nas coletivas, alguns entrevistados faziam perguntas a outros, mudando de lugar e assumindo o papel de entrevistador. Isso fez com que o entrevistador pudesse aprofundar a análise de problemas complexos, e evitou que o pesquisador se constrangesse ao ouvir relatos de práticas que sabia não serem reais, que tinham sua relevância aumentada, e mesmo exageros quanto ao impacto de medidas locais e episódicas, diferentemente do que aconteceu nas entrevistas individuais. Entrevistas coletivas ofereceram aos participantes a oportunidade de se manifestarem e fazerem intercâmbio. No contexto de tais contradições, as condições de produção desses discursos - além de diferentes do ponto de vista do lugar em que estavam os interlocutores - foram diferentes por conta da situação dialógica das 
entrevistas coletivas: as histórias de formação contadas ganharam novos sentidos para quem contava e para quem escutava.

Durante o processo da pesquisa, vivi como pesquisadora um dilema teóricometodológico, em relação ao material empírico disponível a partir das entrevistas coletivas. Do ponto de vista teórico, a necessidade de fundamentar a utilização da entrevista coletiva como estratégia metodológica levou-me a recorrer a Bakhtin, buscando fundamentos para lidar com diversidade, hierarquia e poder na pesquisa em ciências humanas: de acordo com a concepção de linguagem do autor, para entender o que é dito é preciso conhecer não só o enunciado, mas fundamentalmente o contexto da enunciação. Esta concepção e os conceitos apresentados em muitas de suas obras (1982, 1988, 1988a, entre outras) permitem entender que, na produção dos discursos, os lugares que as pessoas ocupam interferem no significado produzido. Ou seja, o contexto é importante para entender o texto. Na enunciação, os lugares e as condições de onde são proferidas as palavras produzem sentidos. A entoação dos discursos, fala.

A decorrência metodológica desta concepção de linguagem é que a totalidade do discurso (o contexto da enunciação) não pode ser perdida. Nesse sentido, o texto de cada entrevista precisa ser analisado na sua integridade e unidade, sem cortes; o texto transcrito a partir de cada entrevista gravada é considerado peça importante na análise das falas. Para delinear esse contexto, foi também elaborado - a partir dos relatos - um breve perfil de cada uma das 57 professoras entrevistadas, contendo alguns aspectos de sua trajetória, formação e escolaridade. Essa estratégia permitiu-nos dar visibilidade aos tópicos da fala que emergiram nos relatos dos professores, fazendo uma apropriação, segundo o que nos pareceu, dos principais tópicos do material das entrevistas. Ouvindo as falas, mergulhando nos textos, atravessando cada transcrição, procuramos captar, compreender, explicitar significados.

É minha intenção, neste terceiro item, focalizar uma das entrevistas coletivas.

\section{PROFISSIONAIS ENTREVISTADAS: TRAJETÓRIAS E CONCEPÇÕES DE MUDANÇA}

O tema da mudança em educação tem acompanhado o debate educacional em várias esferas da vida social, da gestão na sua relação com o Estado até as iniciativas nas escolas. "Conservar ou transformar?" é uma pergunta presente nos manuais de sociologia da educação ou teoria política. Da mesma maneira, palavras 
de ordem relativas à mudança são freqüentes em plataformas eleitorais e agendas de partidos; diretores e coordenadores ao assumirem suas funções estabelecem seu compromisso com o "novo". Essa tônica fica acentuada na sociedade contemporânea, na qual tudo muda muito rápido, o descartável é valorizado, como se no novo que está por vir pudessem ser encontradas formas de mudança, de fazer diferente, respostas, soluções. Todos falam que querem mudar; ninguém quer ser identificado com a manutenção do status quo, ninguém quer ser conservador. Vários trabalhos destacam que o ideário pedagógico tem sido marcado por esta idéia. Para muitos responsáveis pela educação pública ou particular, parece que a mudança do professor ocorre como reciclagem, como se fosse possível jogar fora o superado ou que não é mais desejável ou adequado, assumindo uma posição, teoria ou proposta que, por ser nova, é considerada portadora de uma boa-nova.

A idéia de que é preciso mudar, acompanhada pelo desejo de mudar emergiu em quase todas as entrevistas. Mas foi na entrevista coletiva aqui analisada, feita com nove professoras responsáveis pela educação infantil em municípios de área metropolitana, que o tema emergiu de forma peculiar e a mudança foi mencionada como se constituísse a ação educativa ${ }^{3}$.

Ao entrar para a rede pública, em 1986, uma das professoras entrevistadas percebeu que naquele contexto "índios têm que ser da mesma cor; os trabalhos têm que ser bem parecidos; cuidado com o mural...". Não concordando com aqueles princípios, resolveu:

...vasculhar isso, dar uma mexida nas nossas propostas... para dar um sacode no pedagógico que lá no município só tinha auxiliares de creches, não tinha professores nessas unidades... nós fomos para lá com a intenção realmente do remexer... a gente chegou lá para dar esse atendimento, esse remexer pedagógico. E com isso nós fomos crescendo. (Rosane)

Nessa fala parece estar expressa a idéia de que é possível, ao olhar o velho, ver suas possibilidades de transformação. Mas se a primeira se refere à necessidade de sacudir, outra entrevistada - representante da secretaria estadual - fala da importância de ser puxada:

3 Foram convidadas pessoas responsáveis pela educação infantil das secretarias municipais e estadual de Educação. As entrevistadas eram: três professoras; um membro da Comissão de Educação Infantil do Município, um assistente de coordenação de Educação Infantil,duas Coordenadoras de Educação Infantil e dois representantes da Secretaria Estadual de Educação. 
...meu perfil profissional é um perfil pedagógico, então eu venho desde... os primeiros anos do magistério trabalhando pela educação infantil, trabalhei com alfabetização... trabalhei na roça, zona rural, depois... o perfil da supervisora foi crescendo. Eu entrei para cargos de orientação pedagógica, depois fui para a secretaria. Na secretaria, ...eu estou sempre na parte pedagógica... desenvolvimento curricular, orientação pedagógica para a nossa rede, que é a rede estadual. Então... trabalhando mais naquela linha e tal, tal, tal, tal, de repente você é puxada para uma opção maior. (Elena)

Por outro lado, o relato da trajetória da Coordenadora de Educação Infantil de um município emancipado há três anos traz outra possibilidade de engendrar a mudança do processo; relaciona-se à idéia de ajudar as professoras a trabalhar.

...a creche é um espaço muito... delicado... Enquanto grupo, nós procuramos fazer um trabalho de ajudar esse processo... de formular propostas pedagógicas e ajudar as professoras a trabalhar, então, nós, do grupo da educação infantil é que vamos lá e procuramos ajudar. (Carminha)

Outro aspecto a que a mudança parece estar ligada é a ação que se desempenha ao ser professora. Este aspecto esteve, tanto nesta entrevista quanto nas outras, relacionado à paixão, ao caminhar, à vontade de crescer, ao sonho. Em muitos depoimentos, as professoras reconhecem o desafio que significa permanecer no trabalho com a criança pequena, porque nele se cresce; fica visível também a relevância do papel exercido pela coordenadora de educação infantil de seu município. Outro aspecto diz respeito à paixão que esteve presente de forma marcante nas falas das entrevistadas ${ }^{4}$ : ainda que com freqüência este discurso não se fizesse acompanhar por projetos de fato, como se o amor suprisse a competência, a paixão apareceu entremeada ao compromisso, ao envolvimento profissional e político, constantes na área da educação infantil. Paixão e mudança se aproximariam, assim, seriam ambos contrários à paralisação. No caso desta professora, foram os estudos, os textos e as inquietações que mobilizaram o grupo a buscar conhecimento e a desfazer a visão corrente de que para trabalhar com criança, basta gostar. No seu relato, aparece ainda a importância do mexer:

...foi falando dos estudos que vem fazendo e foi mexendo com o grupo e foi levando texto, e foi envolvendo. E isso fez com que os professores também estudassem. Porque é uma visão que se tem da educação infantil, infelizmente em alguns locais, é

4 Sobre a paixão das falas de profissionais da educação infantil, ver Kramer et al. (2002). 
que "ah é uma pessoa que tem que gostar de criança", não se vê a formação dessa pessoa. (Elvira)

Mexer (como sacudir) e crescer (envolver-se, deslocar para cima, ampliar, estender) apresentam-se assim, também para estas profissionais, como metáforas da mudança. Duas professoras, de outro município, onde coordenam a área de educação infantil, se manifestam e contam suas trajetórias. Falam de busca e de como esbarram em problemas: "comecei a esbarrar nas questões da pré-escola - onde se começa a alfabetização, onde se começa a aprender, o que é a construção do conhecimento. Fui buscando essas pesquisas. Fui buscando esse conhecimento... procurei os caminhos." (Iracema). Essa mesma professora diz que está procurando um caminho de qualificar o profissional, de embasá-lo teoricamente (Iracema), enquanto outra pondera que já estava no momento de mudar e fazer alguma coisa e acrescenta: "E a gente está tentando... seguir um caminho dentro dessa filosofia de projeto. Eu fiz... Nós fizemos o projeto Repensando a Pré-escola..." (Soraia).

Essa forma "eu fiz... nós fizemos" reapareceria em outros depoimentos, nesta e em outras entrevistas, como a indicar uma visão, ainda que intuitiva, de que individual e coletivo se entrecruzam. Além disso, ao falar das dificuldades que professores enfrentam para se atualizar, a mesma professora mostrou-se angustiada com essa situação e intimamente ligada aos professores. E falou sobre seu próprio papel: “...quando a gente está aqui meio que embolada, cheia de interrogações... é meio complicado, parece que vai explodir... a gente vai tentado acalmar, tranqüilizar esse professor através dessas oficinas, dessas palestras, desse estudo..." (Soraia).

Embolação, interrogação, explosão significam mudança? Aqui, o conceito de conhecimento como relâmpago e iluminação de Benjamin ( 1987 , v. I) pode ajudar a compreender este sentido de mudar, não como passo linear, mas como algo que se sacode, que oscila, trepida. Tal como as mudanças de um caleidoscópio, os fragmentos permanecem os mesmos, mas recombinam-se em novas e surpreendentes configurações. Da mesma forma, a visão de mudança presente nas falas das entrevistadas parece aproximar-se do conceito de ambivalência dialética de Bakhtin. Vejamos por quê.

Uma das idéias fundamentais introduzidas por Bakhtin sobre a literatura é a ambivalência. Em oposição à unidade dos contrários, a ambivalência carnavalesca reúne o que é aparentemente incompatível: o riso e o choro, sério e o grotesco, o profano e o sagrado, a vida e a morte, o homem e a besta. Essa ambivalência cultural originar-se-ia para Bakhtin no fim da Idade Média e início do Renascimento, no 
carnaval como acontecimento ao mesmo tempo popular e crítico. Se a cultura oficial só reconhecia a diferença absoluta e o monólogo, o carnaval põe em cena a coexistência dos opostos. A polifonia, na qual todo discurso aparece como relativo, substitui o discurso monológico dos dominantes (Bakhtin, 1999). Enquanto a dialética hegeliana propõe a superação de tese e antítese numa síntese dos contrários, a dialética bakhtiniana supõe que a ambigüidade se mantém: trata-se de uma dialética dialógica em que a atitude com o outro, com o diferente, com o inverso, é de aceitação e tolerância. As contradições permanecem vivas e tensas; em vez de evolução, temos a explosão, um piscar de olhos no qual tudo permanece e ao mesmo tempo muda. A ambivalência toma, nos escritos de Bakhtin, um sentido crítico; que se opõe ao monólogo, ao discurso autoritário. Contra a idéia de que é possível optar entre isto ou aquilo, em Bakhtin (1999), o discurso crítico é ambivalente, comportando simultaneamente isto e aquilo, e aqui reside seu elemento libertador e positivo. No que se refere à educação, esta maneira de entender a mudança pareceme humana e viável por pressupor que o velho e o novo convivem sem que a teoria ou a concepção hegemônica de um determinado momento sufoque a prática. A mudança se dá pela coexistência de posições teórico-práticas diversas que se encontram, chocam, dialogam, e não por uma evolução linear e autoritária em que, por decreto, o velho seria dispensado e o novo adotado.

\title{
PROVISÓRIO, INSTÁVEL, ACOMODADO: PONTOS POSITIVOS E PROBLEMAS
}

\author{
Quando estamos nos olhando, dois mundos diferentes se \\ refletem na pupila dos nossos olhos. Graças a posiçôes \\ apropriadas, é possível reduzir ao mínimo essa diferença dos \\ horizontes, mas para eliminá-la totalmente, seria preciso fundir-
} se em um, tornar-se um único homem.

Bakhtin, 1992, p. 43

Reunidas em grupos, as entrevistadas analisaram os problemas e conquistas da educação infantil e discutiram seus pontos de vista. Os relatos, logo após essas discussões, permitem-nos perceber os tópicos levantados. Entre outros temas, as professoras falam da provisoriedade e instabilidade da própria prefeitura - "acontece na gestão municipal ou estadual: hoje é um prefeito, amanhã, outro" (Élen) - e da provisoriedade e instabilidade da condição do professor da educação infantil:

.... nosso problema enquanto qualificação do profissional, da formação do professor da educação infantil - é que ele não éprofessor da educação infantil, das redes públi- 
cas, ele está. Então hoje, se investe nesse professor... se faz um trabalho de um ano inteiro de qualificação... e ano que vem esse professor muda de turma. (Iracema)

E a mesma entrevistada que trouxe o tema da mudança, falando de "sacode", ressalta a busca e o valor da reflexão sobre a prática. Diz:

...esse momento de reconhecimento da qualidade desse trabalho, que a gente está tão preocupado, ele não pode se perder nunca dos dados históricos. O professor tem que estar buscando na história sempre alguma coisa referente à educação infantil... O profissional que tem a possibilidade de estudo reflete sobre o seu pensar pedagógico. Valorizado, tendo tempo para estudo ele reflete, com certeza, todo seu pensar pedagógico. (Rosane)

Como no início da entrevista, ela volta a falar sobre o sacode, relacionandoo agora a compromisso. E compromisso parece implicar também liberdade.

...não adianta dizer "aqui está bonito, então eu vou plantar mais uma florzinha para ficar melhor". Não, tem que ter uma situação efetiva mesmo de amparo. De amparo legislativo, mas de amparo financeiro também... que a gente tem que estar se virando... tem que estar se sacudindo para organizar... tem que ter um compromisso efetivo, não pode ser um compromisso estritamente legislativo. Tem que ter uma proposta maior. (Rosane)

No contexto discursivo da entrevista, parece que ao mesmo tempo em que é preciso sacudir e buscar, é preciso amparar e se virar! Nessa mesma linha, compromisso pressupõe também desacomodar, alterar o lugar das coisas:

...tem aquele que tem informação, que sabe e cai no comodismo... é muito mais fácil. Porque tem uma carga enorme de família, de filho, de outro trabalho, de outro tudo. Vou ter que chegar aqui, ainda sentar, botar um pouquinho para cá "ah, isso vai me dar muito trabalho!”. Pronto. Pega essa folhinha, dá um deverzinho, massinha, dá massinha, deixa ele meia hora ali... Ele sabe, tem conhecimento, ele sabe a responsabilidade nem que aquilo lá no fundo doa ele, mas naquele momento para ele é mais cômodo, é mais cômodo não pôr aquilo tudo que ele sabe... em prática. (Soraia)

...lá na nossa realidade eu tenho observado bastante, as pessoas que têm medo de agir. Eu acho que pode estar embutido num comodismo sim. (Iracema) 
é mais fácil, eu acho, não saber, porque aí eu tenho pouca responsabilidade. (Soraia)

...às vezes eles não falam, não é porque não tem vontade, não tem interesse. Não está prestando atenção... ainda não se apropriou da liberdade de estar falando. (Rosane)

Esse depoimento sobre o professor como alguém que precisa se apropriar da liberdade evoca claramente Paulo Freire (1982). Por outro lado, as entrevistadas trouxeram aqui a questão polêmica da relação entre a teoria e a prática. Sua abordagem oferece elementos interessantes para a reflexão, na medida em que levantam modos alternativos de olhar a prática e sugerem que um professor pode:

I. Ter a teoria, compreender os textos lidos, mas não se mexer, por comodismo.

2. Compreender mas ter medo de agir por falta de compromisso.

3. Não saber, não conhecer a teoria.

4. Não conseguir pronunciar a sua palavra; não se apropriar da liberdade de dizer.

A pouca formação foi criticada, mas as entrevistadas questionaram também a formação que expropria o professor da sua prática. Entendemos que a crítica se dirige à ausência de práxis, da teoria como reflexão sobre e para a prática, feita com o outro, como leitura do mundo, crítica e ativa, que reúne saber, fazer e falar. Além disso, percebemos nestas falas que mudar parece ainda se vincular a desestabilizar. Como quando a Soraia diz: "que alguém está tirando o chão concreto dele...".

Ao mesmo tempo, foram apontadas muitas dificuldades para mudar. Dentre elas, chamam a atenção os relatos de professoras entrevistadas que, por várias vezes, reafirmam existirem professores que se recusam a transformar a prática, apesar de atualizados com as discussões mais recentes. Uma diz que "às vezes há uma resistência... histórica, ao novo conhecimento. Que quando a gente conhece a gente paga um preço para aquilo, é uma responsabilidade de fazer aquilo que as outras pessoas não aprenderam". Outra pondera: "até ousar, se expor, investir e fazer alguma coisa que seja novo para você, e se der errado?". Ainda outra professora indaga: "e se der certo?", criticando aqueles que têm medo de fazer e julgam que a ousadia de mudar traz resultados negativos, nunca positivos. Questiona também:

....aquele professor que tem a teoria, que sabe, que entende [mas], na prática ele não consegue desenvolver. Ele não faz. [...] a gente tem a cultura do "se der erra- 
do?", sempre. A gente não pensa nunca que vai dar certo, mas "se der errado". Aqui é o diretor vai me chamar a atenção, o pai não vai gostar, o outro... então eu prefiro nem ousar. (Soraia)

Relacionando a questão ao momento político do país, outra entrevistada comenta:

nós estamos dentro de uma roda. E nosso país tem caminhado muito por uma linha... de desesperança, de confusões... isso também afeta muito... O professor parece desacreditado do seu trabalho quando ele diz que não vai fazer e o nosso compromisso é também lutar contra esse caminho de desesperança que a gente tem vivido... Na rua, na televisão, todo tempo a mensagem que é passada para nós é esse caminho tortuoso que a gente tem à frente de lidar com as crianças, com as suas necessidades, as dificuldades financeiras, o salário que é pequeno e uma porção de coisas que, sem estrutura, a gente acaba convivendo nessa roda. (Carminha)

Diante desse depoimento, outra pondera:

Eu gosto muito de uma frase... eu sempre falo para eles: quando você era menino [perguntavam] o que, menino, você vai ser quando crescer? Eles respondem assim: se me perguntassem isso agora, na idade adulta, eu responderia que eu gostaria de ser menino. Então o professor, principalmente da educação infantil... ele tem essa facilidade de virar esse menino. Inclusive tem essa facilidade de ter a vontade de voltar. (Rosane)

Ao fazê-lo, essa professora parece evocar o conceito de infância em Walter Benjamin (1987, v.2), categoria central da história como possibilidade de refazer e de voltar.

\section{A TÍTULO DE CONCLUSÃO: AMBIGÜIDADES DA MUDANÇA}

Sacudir, remexer, desacomodar: evocam ebulição e, de algum modo, podem ser compreendidos como metáforas de mudanças sem deslocamento visível de tempo. Sugerem explosão. Lembram a dialética do instante de Walter Benjamin ou dialética imobilizada (1987); a tensão ou ambivalência dialética de Bakhtin. Configuram-se como pequenos deslocamentos de lugar e têm significa- 
do diferente de outras concepções de mudança - mais freqüentemente encontradas ou ouvidas na área da educação - tais como as implícitas nas idéias de buscar, procurar, passagem, transição e que evocam metáforas de deslocamentos mais amplos de lugar; mudanças que são introduzidas de fora para dentro, projetos elaborados em outros contextos ou momentos históricos e que seriam uma resposta se aplicados ou implantados nos respectivos contextos.

Mexer, sacudir, ser puxada. Cobrar, acomodar-se, exigir, mudar. Querer mudar. Ser como criança. Voltar. Sacudir e mexer parecem se relacionar a mudanças nas práticas pedagógicas mais tênues, imperceptíveis, mas fortes. "Sacudir e amparar, ajudar"; "mexer, remexer e apoiar" são aspectos interessantes nesse contexto. Dão, inclusive, importantes lições, pois escapam de jargões comuns no ideário pedagógico, freqüentemente marcado pelo discurso do novo como "novo conhecimento", "nova concepção", "novo olhar". Sacudir parece interessante, enquanto concepção de mudança, porque embora suponha que o outro age sobre a realidade, incorpora o que já existe e é feito. Diferentemente da idéia de mudança ligada à continuidade, à linearidade presente-passado-futuro, comum no campo da educação, no qual, com freqüência, se atribui ao passado a origem do problema e se joga a solução ou a mudança para o futuro, deixando intocado o presente, as metáforas de alterar o lugar (sacudindo) parecem presentificar a possibilidade de mudar, de fazer diferente, de deslocar. É interessante notar que não constatamos, nesta entrevista, expressões como "nova prática" ou "nova teoria". Talvez, na visão dessas professoras, a mudança nas práticas, nos modos de fazer, só se torna possível quando se sacodem as estruturas. Talvez, para além do aparente ou para além do discurso esperado, a transformação signifique encontrar-se no chão, amparada, mas estando ali, simultaneamente, em movimento intenso. Manter-se na roda, sem tirar o chão do outro, sem perder seu próprio chão, sendo puxada, incentivada, acionada, para cima, continuando no lugar, vibrando, mantendo-se em mudança, embora imperceptível, sem estardalhaço, sem holofote nem espetáculo. Parece ser essa a mudança de que precisamos. $\bigcirc$ que essa entrevista ensina é que é preciso mexer, movimentar o pedagógico de modo que a mudança possa garantir que as pessoas continuem crescendo e permaneçam humildes, isto é, humanas, sem alardear o conhecimento científico supostamente novo como se fossem medalhas. Não se trata de mérito, mas da luta de muitos. Luta diária, quieta. O conceito de ambivalência dialética (Bakhtin, 1981, 1999) ofereceu a chave para a compreensão dessa forma ambígua de compreender a mudança. 
Esse movimento para a mudança parece relacionar-se a outro aspecto também presente nas entrevistas, e que analisei em outro texto: a paixão. Política e paixão se entrecruzam nos depoimentos. Ora enfatizando o compromisso profissional, com a criança ou com a cidade, ora contando dos obstáculos que tiveram de enfrentar para estudar e da luta por melhores condições para o trabalho, as entrevistadas falaram de engajamento profissional e entusiasmo no trabalho, necessidade de mudança e envolvimento. Além disso, há que considerar, no que diz respeito às condições de produção destes discursos (Bakhtin, 1988), que estavam presentes nesta entrevista não só coordenadores de educação infantil dos municípios, mas também duas representantes de instâncias da sociedade civil, indicados pela secretaria de educação para representá-la, além de duas profissionais de um município recém-emancipado, visivelmente motivadas por sua possibilidade de começar. $\bigcirc$ lugar de onde foram pronunciados esses discursos, o contexto de sua enunciação determinou, portanto, as palavras proferidas e seus significados. É preciso considerar também a quem esse discurso se dirige, quais os seus destinatários, como aborda Bakhtin: neste caso, são professores e alunos de uma universidade conceituada, situada em uma grande cidade do estado, desenvolvendo uma pesquisa. Será que o discurso sobre a mudança não foi construído também a partir do que os entrevistados julgaram que os entrevistadores esperavam ouvir?

Enfim, as entrevistas coletivas ofereceram aos participantes a oportunidade de se manifestarem e pronunciarem a sua contrapalavra. Nessa entrevista, aqui analisada, o tema da mudança foi abordado de modo original - a metáfora de sacudir e os conceitos de ambivalência dialética e dialogismo forneceram um interessante instrumento conceitual para a análise. Na pesquisa, a idéia de que é preciso mudar junto com o desejo de mudar emergiu em quase todas as entrevistas, mas foi nesta entrevista com nove professoras que a mudança emergiu como se constituísse a ação educativa. Ao relatar que não concordava com a prática vivida e que resolveu dar um sacode no pedagógico, a professora forneceu a chave para a escrita deste texto, que constitui apenas uma dentre as muitas aproximações possíveis que temos feito dos discursos das entrevistadas.

\section{REFERÊNCIAS BIBLIOGRÁFICAS}

AMORIM, M. O Pesquisador e seu outro: Bakhtin e as ciências humanas. Rio de Janeiro: Musa, 2001. 
BAKHTIN, M. A Cultura popular na ldade Média e no Renascimento: o contexto de François Rabelais. São Paulo: Hucitec, 1999.

Estética da criação verbal. São Paulo: Martins Fontes, 1992.

Estética de la creación verbal. Buenos Aires: Sigla Veintuno, 1982.

Problemas da poética de Dostoiévski. Rio de Janeiro: Forense Universitá-

ria, |981.

Questões de literatura e de estética. São Paulo: Hucitec, 1988.

Marxismo e filosofia da linguagem. São Paulo: Hucitec, 1988a.

BENJAMIN, W. Obras escolhidas. São Paulo: Brasiliense, 1987, v. I. Magia e técnica, arte e política.

Obras escolhidas. São Paulo: Brasiliense, 1987, v.2. Rua de mão única.

FREIRE, P. Ação cultural para a liberdade. Rio de Janeiro: Paz e Terra, 1982.

GOODSON, I. F. Studying teachers lives. London: Routledge, 1992.

KRAMER, S. Alfabetização, leitura e escrita: formação de professores em curso. São Paulo: Ática, 2001.

Entrevistas coletivas: alternativa para lidar com diversidade, hierarquia e poder na pesquisa em ciências humanas. In: FREITAS, M. T. A.; KRAMER, S.; SOUZA, S. J. (orgs.) Ciências humanas e pesquisa: leituras de Bakhtin. São Paulo: Cortez, 2003. p.57-76.

Por entre as pedras: arma e sonho na escola: leitura, escrita e formação de professores. São Paulo: Ática, 1993.

KRAMER, S.; SOUZA, S. J. (orgs.). Histórias de professores: leitura, escrita e pesquisa em educação. São Paulo: Ática, 1996.

KRAMER, S. et al. Formaçãp de profissionais da educação infantil no Estado do Rio de Janeiro: relatório de pesquisa. Rio de Janeiro: Ravil, 2001

Nos relatos de professores, conquistas e ambigüidades da educação infantil. Cadernos do Departamento de Educação PUC-Rio, n. 62, p. 10 -14, set. 2002.

LÉLIS, I. A. A Polissemia do magistério: entre mitos e histórias. Rio de Janeiro, 1996. Tese (Dout.) PUC.

LISPECTOR, C. Água viva. Rio de Janeiro: Artenova, 1973. 
NASCIMENTO, A. Educação Infantil no contexto das políticas públicas: análise das propostas pedagógicas dos municípios do Estado do Rio de Janeiro. Rio de Janeiro: PUC. [Monografia do Curso de Especialização em Educação Infantil.]

NÓVOA, A. Profissão: professor. Porto: Porto, 1991.

Vidas de professores. Porto: Porto, 1992.

ZIMA, P. L'Ambivalence dialectique: entre Benjamín et Bakhitne. Revue d'Esthétique, Paris, Centre National de la Recherche Scientifique, n. I, p. I31-140, I981. (Nouvelle Série.)

Recebido em: dezembro 2003

Aprovado para publicação em: janeiro 2004 